\title{
PRANCANGAN SISTEM GROUNDING GENERATOR UNTUK SKEMA PROTEKSI BELITAN STATOR GENERATOR 100\% MENGGUNAKAN NGT
}

\author{
Ali Mashar, Kholiq Hernawan, Maula Zahara Firdausi \\ Jurusan Teknik Konversi Energi - Politeknik Negeri Bandung \\ Jalan Gegerkalong Hilir, Ciwaruga - Bandung 45551 \\ Email: amashar69@gmail.com
}

\begin{abstract}
ABSTRAKSI
Untuk menerapkan sistem proteksi stator generator $100 \%$ seperti skema neutral overvoltage fundamental (59Gn), undervoltage third harmonics $(27 \mathrm{~N} 3)$ perlu perancangan sistem pembumian impedansi tinggi menggunakan Neutral Grounding Transformer (NGT). NGT harus bisa mereduksi arus gangguan tanah. Paper ini akan mengkaji bagaimana merancang NGT untuk keperluan seperti di atas. Dalam perangan ini dimulai dari spesifikasi generator, trafo-trafo dan perlengkapan jaringan lainnya. Dalam paper ini akan dikaji penentuan kapasitas trafo NGT dan resitansi sekundernya. Untuk dapat mendemonstrasikan metode perancangan ini dengan baik, paper ini menggunakan pokok kajian generator dari salah satu PLTU di Indonesia dengan kapasitas 802 MVA, 22,8 kV. Dari hasil studi diperoleh bahwa NGT hasil rancangan memiliki kapasitas hanya $37 \mathrm{kVA}, 15000 \mathrm{~V} / 240 \mathrm{~V}$ dengan resistor sekunder sebesar $0,38 \Omega, 150 \mathrm{~kW}$.
\end{abstract}

Kata kunci: proteksi stator generator 100\%, NGT, kapasitas, resistansi wsekunder.

\section{A. Pendahuluan}

Generator merupakan komponen utama dalam suatu pembangkit tenaga listrik (power plant) yang harus dijaga keamanannya dari semua jenis gangguan yang kemungkinan terjadi. Hal ini tidak lepas dari peranan generator yang demikian vital dalam penyediaan tenaga listrik selain yang demikian mahal harganya dan juga biaya maintenancenya bila mengalami kerusakan. Sehubungan dengan itu, mesin tersebut mendapatkan sistem proteksi (pengamanan) secara berlapis, baik proteksi dari kesalahan (gangguan) internal maupun eksternal.

Proteksi generator secara internal meliputi antara lain proteksi stator, rotor, dan sistem eksaiternya. Secara eksternal nerupakan proteksi yang mengamankan generator dari kesalahan-kesalahan dari luar seperti over current, overload, over/under frekuensi dan tegangan.
Dalam kaitannya dengan proteksi internal generator telah diterapkan bermacam-macam skema proteksi seperti differential relay, ground fault relay untuk mengamankan belitan stator dan rotor generator. Namun dengan semakin meningkatnya kapasitas generator dengan tegangan pembangkitan yang semakin tinggi (20 kV ke atas), menyebabkan meningkatnya kapasitansi generator dan peralatan-peralatan bantunya. Kapasitansi yang tinggi membuat relay-relay konvensional menurun sensitivitasnya. Karena itu, kemudian dikembangkan sistem proteksi dengan skema baru, seperti neutral overvoltage relay fundamental, neutral undervoltage third harmonic relay, dan subharmonic injection relay seperti yang ditunjukkan pada Gambar 1. Untuk kepentingan proteksi dengan skema-skema ini memerlukan sistem grounding yang sesuai dan yang umum digunakanadalah sistem grounding yang menggunakan Neutral Grounding Transfomer (NGT). 
Atas dasar itu perancangan sistem grounding ini menjadi sangat penting dilakukan untuk melindungi generator dari gangguan internal. Yang menjadi perhatian dalam paper ini adalah yang terkait dengan proteksi belitan stator generator.

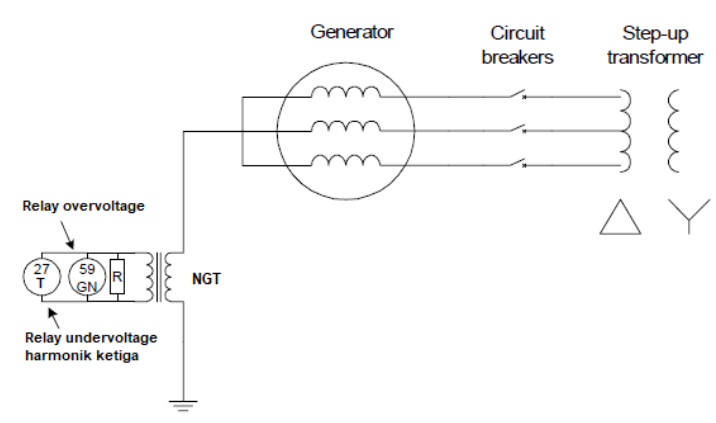

Gambar 1. Skema proteksi gangguan tanah

\section{B. Generator Sinkron dan kegagalan isolasi}

Pada generator-generator yang berkapasitas besar, menggunakan pembangkitan yang relatif tinggi $(20 \mathrm{kV})$ sehingga kegagalan isolasi sangat tinggi kemungkinannya untuk terjadi. Bila terjadi kegagalan isolasi stator akan berdampak besar pada kerusakan kumparan dan juga inti stator. Kalau kerusakan terjadi pada inti stator akan jauh lebih fatal dampak kerugian yang dialami. Oleh karena itu, stator harus benar-benar dilindungi dari kesalahan-kesalahan semacam ini.

Banyak penyebab terjadinya kegagalan isolasi stator ini walaupun dalam desainnya sudah diperhitungkan dengan baik. Dalam hal ini [1] 2016) telah menjelaskan secara rinci tentang hal ini, di mana dikatakan bahwa kegagalan isolasi stator bisa diakibatkan oleh faktor-faktor: panas, listrik, mekanis, dan lingkungan.

\section{Ground Fault pada Generator}

Ada banyak gangguan yang bisa terjadi pada generator baik secara internal maupun eksternal. Salah satu gangguan internal generator adalah gangguan ke tanah (ground fault). Gangguan ini dapat dikelompokkan gangguan simetris dan asimetris [2].

1. Gangguan simetris adalah gangguan yang terjadi pada fasa-fasa-fasa-tanah (L-L-L-G) dan fasa-fasa-fasa (L-L-L). Gangguan ini sangat jarang terjadi, hanya $2-5 \%$ tapi sangat berbahaya.

2. Gangguan asimetris yaitu: fasa-fasa (L$\mathrm{L}$ ), fasa-tanah (L-G), dan fasa-fasatanah (L-L-G). Di antara gangguangangguan tersebut, gangguan fasa tanah (L-G) paling sering terjadi, mencapai $65-70 \%$.

Fenomena gangguan tanah (ground fault) fasa-tanah secara skematik ditunjukkan pada Gambar 2.

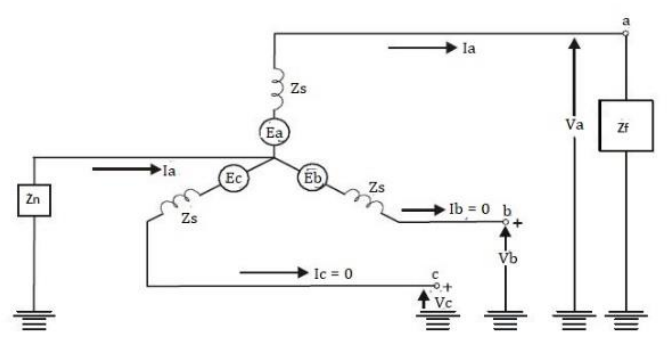

Gambar 2. Diagram Skematik Gangguan fasa - tanah

Bila terjadi gangguan tanah seperti ini, maka arus yang mengalir ke tanah hanyalah arus dari saluran yang mengalami gangguan saja (misal: fasa a), sedangkan fasa/saluran yang lain (fasa b dan c) tetap sehat. Besar arus gangguan akan ditentukan oleh tegangan yang dibangkitkan generator dan impedansi hubung singkatnya. Karena impedansi termasuk impedansi pembumiannya, maka jelas bahwa impedansi pembumian ini akan sangat menentukan besar arus gangguan ini.

\section{Sistem Pembumian Impedansi tinggi}

Sistem pembumian ini adalah sistem yang menghubungkan netral generator dengan bumi (tanah). Standar [3] memuat jenis-jenis metode pembumian netral generator, mulai dari pembumian langsung (solid grounded) sampai dengan yang 
tanpa pembumian (un-grounded). Pembumian langsung paling murah namun berimpedansi sangat rendah (nol) sehingga ketika terjadi gangguan tanah akan memberikan arus gangguan yang sangat besar.

Ketika arus melampaui batas yang diizinkan, inti stator akan panas, kemudian isolasi gulungan stator akan rusak, akan mengakibatkan hubung pendek antar lilitan (turn to turn) atau hubungan pendek antar fase, yang mengakibatkan meluasnya gangguan. Sebaliknya, bila tanpa grounding, arus gangguan tanah hanya berupa arus kapasitif yang kecil saja. Namun, ketika arus kapasitif melampaui harga tertentu (5A), akan terjadi arcing yang terus menerus. Dengan arc listrik yang intermittent akan mengakibatkan terjadinya overvoltage pada fasa-fasa yang sehat (1,73 kali).

Meningkatnya tegangan ini juga meningkatkan stress isolasinya sehingga memungkinkan terjadinya kegagalan isolasi (break-down) dan akan sangat membahayakan generator.

Inilah alasan mengapa pada generatorgenerator sinkron yang berkapasitas tinggi sistem pembumiannya menggunakan pembumian dengan impedansi tinggi yang salah satunya adalah Neutral Grounded Transformer (NGT).

\section{E. Neutral Grounded Transformer (NGT)}

Neutral Grounded Transformer (NGT) adalah metode pembumian yang menggunakan trafo distribusi yang primernya dipasang antara netral generator dan tanah, sedangkan pada sekunder trafo dipasang sebuah resistor seperti ditunjukkan pada Gambar 2. Kalau terjadi kesalahan atau gangguan impedansi nol (bolted), tegangan pada primer trafo sama dengan tegangan pembangkitannya (L-N). Oleh karena itu, rating tegangan transformator pembumian ini dipilih sama, atau sedikit lebih besar dari tegangan fasa - netral (ground) nominal generator sebagai antisipasi tegangan berlebih. Resistor sekunder trafo dipilih dengan resistansi yang relatif tinggi agar ketika terjadi kesalahan tanah dapat membatasi arus gangguan primer antara 3-25 A [3], dan berdasarkan [5] arus dibatasi maksimum 1 A. Dengan demikian generator bisa dilindungi dari kerusakan akibat arus gangguan tanah.

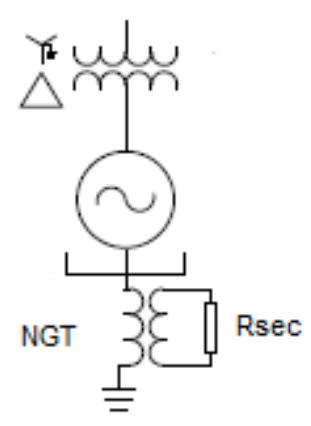

Gambar 3. Pembumian metode NGT

Rsec ini dipasang untuk mendapatkan reistansi (impedansi) primer secara memadai agar bila terjadi gangguan fasa-tanah, arusnya bisa direduksi seperti yang diinginkan. Hubungan antara Rsec dan Rpri bisa dilihat lagi rangkaian rangkaian ekivalen trafo seperti yang ditunjukkan pada Gambar 4.

Gambar ini menunjukkan $\mathrm{R}_{1}$ dan $\mathrm{R}_{2}$ merupakan resistansi belitan primer dan sekunder secara berturut-turut. Sedangkan reaktansi induktif $\mathrm{X}_{\mathrm{L} 1}$ dan $\mathrm{X}_{\mathrm{L} 2}$ merupakan fluksi bocor pada belitan primer dan sekunder yang berpengaruh terhadap penurunan tegangan [7].

Rangkaian ekivalen transformator dapat dilihat dari sisi primer maupun sisi sekunder. Dari Gambar 5, rangkaian ekivalen bila dilihat dari sisi primer [8]:

$$
\begin{aligned}
\mathbf{X}_{\mathbf{L} 2}^{\prime} & =\mathbf{X}_{\mathbf{L} 2}\left(\mathbf{N}_{1} / \mathbf{N}_{2}\right)^{2} \\
\mathbf{R}_{2}^{\prime} & =\mathbf{R}_{2}\left(\mathbf{N}_{1} / \mathbf{N}_{2}\right)^{2}
\end{aligned}
$$




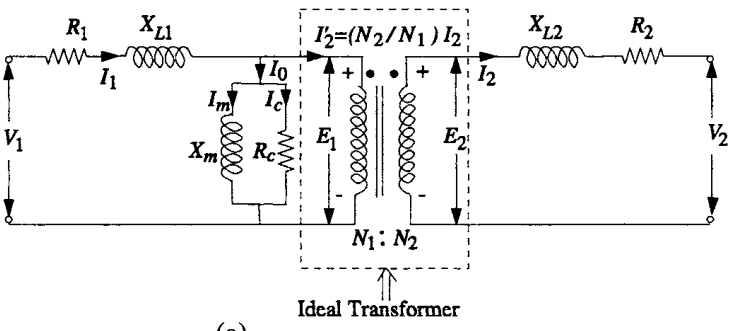

(a)

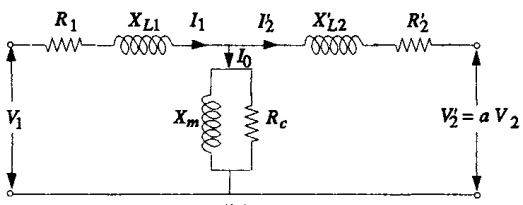

(b)

Gambar 4. Rangkaian ekivalen trafo dari sisi primer

Dikaitkan dengan NGT, nilai tahanan primer dilihat sisi netral generator ekivalen berlaku

$$
\mathrm{R}_{\mathrm{p}}=\mathrm{R}_{\mathrm{s}} \times \mathrm{N}^{2}
$$

Dimana $: \mathrm{R}_{\mathrm{p}}$ adalah resistansi primer

$\mathrm{R}_{\mathrm{s}}$ adalah resistansi sekunder

$\mathrm{N}$ adalah perbandingan

transformasi trafo

pembumian

\section{F. Hasil dan Pembahasan}

\section{1) Spesifikasi Generator dan trafo utama}

Perancangan NGT tidak lepas dari generator dan sistem jaringannya. Untuk memperjelas dan mempertajam bahasan dan kajian dalam paper ini, sebagai obyek dipilih sebuah generator pada salah satu PLTU yang termasuk berkapasitas tinggi, yaitu 802 MVA dan tegangan $22,8 \mathrm{kV}, 50$ Hz. Informasi yang dibutuhkan untuk kajian ini adalah data spesifikasi kapasitansi generator, trafo-trafo dan kelengkapan bantu lainnya. Data spesifikasi yang dimaksud disajikan secara lengkap pada Tabel 1 meliputi: generator, generator transformer (GT) dan Unit Auxiliary Transformer (UAT) lengkap dengan surge absorber dan komponen lainnya.

Tabel 1. Spesifikasi generator dan jaringannya

\begin{tabular}{|c|c|c|}
\hline \multicolumn{2}{|c|}{ Peralatan } & $\begin{array}{c}\text { Kapasitansi fasa } \\
-\operatorname{tanah}(\text { per } 1 \phi) \\
\left(\mathrm{C}_{0}\right)(\mu \mathrm{F})\end{array}$ \\
\hline \multicolumn{2}{|c|}{$\begin{array}{lr}\text { Generator } & 802 \\
\text { MVA, 22,8 } & \mathrm{kV} \\
\left(\mathrm{C}_{\text {Gen }}\right) & \end{array}$} & $0,33 \mu \mathrm{F}$ \\
\hline \multirow{3}{*}{$\begin{array}{l}\text { Surge } \\
\text { absorber }\end{array}$} & $\mathrm{Cs}_{\mathrm{a} 1}$ & $0,13 \mu \mathrm{F}$ \\
\hline & $\mathrm{Cs}_{\mathrm{a} 2}$ & $0,13 \mu \mathrm{F}$ \\
\hline & $\mathrm{C}_{\mathrm{VT}}$ & $0,10 \mu \mathrm{F}$ \\
\hline \multirow{4}{*}{ Trafo } & $\mathrm{C}_{\mathrm{GT}}$ & $0,43 \times 10^{-2} \mu \mathrm{F}$ \\
\hline & $\mathrm{C}_{\mathrm{UT1}}$ & $0,11 \times 10^{-1} \mu \mathrm{F}$ \\
\hline & $\mathrm{C}_{\mathrm{UT2}}$ & $0,11 \times 10^{-1} \mu \mathrm{F}$ \\
\hline & $\mathrm{C}_{\text {Ext }}$ & $0,02 \times 10^{-2} \mu \mathrm{F}$ \\
\hline $\begin{array}{l}\text { IPB } \\
\text { (Isolated } \\
\text { Phase } \\
\text { Bus) }\end{array}$ & $\mathrm{C}_{\mathrm{IPB}}$ & $\begin{array}{c}0,925 \times 10^{-3} \\
\mu \mathrm{F}\end{array}$ \\
\hline
\end{tabular}

\section{2) Penentuan resistansi primer trafo (Rn)}

Berikut ini adalah proses perhitungan resistansi primer trafo.

Kapasitansi terhadap netral merupakan nilai semua kapasitansi yang terhubung paralel, sehingga total kapasitansi sistem adalah:

$\left(\mathrm{C}_{0}\right)=\mathrm{C}_{\mathrm{Gen}}+\mathrm{Cs}_{\mathrm{a} 1}+\mathrm{Cs}_{\mathrm{a} 2}+\mathrm{C}_{\mathrm{VT}}+\mathrm{C}_{\mathrm{GT}}+$

$\mathrm{C}_{\mathrm{UT} 1}+\mathrm{C}_{\mathrm{UT} 2}+\mathrm{C}_{\mathrm{Ext}}+\mathrm{C}_{\mathrm{IPB}}=0,717425 \mu \mathrm{F}$

Dengan demikian nilai reaktansi kapasitif terhadap netral dapat dihitung:

$$
\begin{gathered}
X_{c o}=\frac{1}{\omega C o} \\
X_{c o}=\frac{1}{2 \pi f C o} \\
X_{c o}=\frac{1}{2 x \pi \times 50 \times 0,717425 \times 10^{-6}} \\
X_{c o}=4436,84 \Omega
\end{gathered}
$$

Berdasarkan nilai reaktansi kapasitif terhadap netral diketahui, maka reaktansi 
kapasitif terhadap ground $\left(X_{c g}\right)$ dapat dihitung:

$$
\begin{aligned}
& X_{c g}=\frac{X c o}{3 \phi} \\
& X_{c g}=\frac{4436,84 \Omega}{3} \\
& X_{c g}=1478,94 \Omega
\end{aligned}
$$

Dalam standar nilai resistor netral primer $\left(R_{n}\right)$ dipilih sama dengan $X_{c g}$, atau:

$$
\begin{aligned}
& R_{n}=X_{c g} \\
& R n=1478,94 \Omega
\end{aligned}
$$

Dengan demikian, nilai resistansi primer netral terhadap ground $\mathrm{Rn}$ adalah $1478,94 \Omega$. Kemudian dari nilai ini akan ditentukan nilai resistansi sekunder Rsec, namun sebelumnya perlu dicari rasio (perbandingan transfoirmasi) trafo.

\section{3) Perbandingan transformasi (rasio) trafo}

Rasio trafo merupakan perbandingan antara tegangan primer dan sekunder (Vp/Vsec). Seperti yang sudah disampaikan pada bagian sebelumnya bahwa tegangan primer NGT minimal harus sama dengan tegangan pembangkitan satu fasa, dan untuk mengantisipasi adanya tegangan lebih. maka dalam hal ini tegangan primer dipilih lebih tinggi.

Diketahui tegangan nominal generator $22.800 \mathrm{~V}$, maka tegangan perfasanya adalah $22800 / \sqrt{ } 3=13164 \mathrm{~V}$. Dari tegangan per fasa nominal generator ini dipilih trafo yang umum dan di atasnya sedikit, yaitu: 15000 V. Sedangkan tegangan sekunder ada dua pilihan, yaitu: $110 \mathrm{~V}$ atau $240 \mathrm{~V}$. Dalam kajian ini dipilih tegangan nominal sekunder $240 \mathrm{~V}$. Dengan demikian rasio trafo NGT:

$$
N=\frac{15000}{240}=62,5
$$

3) Penentuan resistor sekunder $\left(\boldsymbol{R}_{\text {sec }}\right)$

$$
\begin{aligned}
R_{\text {sec }} & =\frac{R_{n}}{N^{2}} \\
R_{\text {sec }} & =\frac{1478,94}{62,5^{2}} \\
R_{\text {sec }} & =0,38 \Omega
\end{aligned}
$$

\section{4) Penentuan kapasitas daya Rsec}

Kapasitas daya resistor sekunder dapat ditentukan berdasarkan daya yang didisipasikan pada resistor. Oleh karena itu, perlu diketahui terlebih dahulu arus sekundernya.

Arus sekunder adalah:

$$
\begin{aligned}
& I_{\text {sec }}=\frac{V_{\text {sec }}}{R_{\text {sec }}} \\
& I_{\text {sec }}=\frac{240}{0,38}=631,58 \mathrm{~A}
\end{aligned}
$$

Dengan demikian, kapasitas daya resistor sekunder ketika terjadi gangguan (Psec)

$$
\begin{aligned}
\text { Psec } & =I_{\text {sec }}^{2} \times R_{\text {sec }} \\
\text { Psec } & =631,58^{2} \times 0,38 \\
\text { Psec } & =151.579,45 \mathrm{~W} \\
& \approx 150 \mathrm{~kW}
\end{aligned}
$$

Jadi, bisa disimpulkan bahwa resistor sekunder memiliki spesifikasi $0,38 \Omega$ dengan kapasitas daya $150 \mathrm{~kW}$.

\section{5) Penentuan Kapasitas trafo NGT}

Kapasitas trafo dapat ditentukan sebagai berikut:

$$
\begin{aligned}
S & =\frac{P_{\text {sec }}}{\cos \theta} \\
& =\frac{150}{0,85} \\
= & 176,47 \mathrm{kVA} \mathrm{kVA \approx 175} \mathrm{kVA}
\end{aligned}
$$

Dari perhitungan ini menunjukkan bahwa kapasitas NGT adalah 175 kVA. Terkait dengan penentuan kapasitas trafo ini, karena bekerjanya hanya pada saat terjadi gangguan dalam waktu yang sangat pendek, maka kapasitas trafo bisa diturunkan kapasitasnya dengan memperhatikan durasi overloadnya. Berapa besar penurunan yang bisa dilakukan, dan bila tidak ada petunjuk dari pabrikan, Dann and Montsinger memberikan bantuan sebagaimana dimuat pada [4] dan [6] seperti pada Tabel 2. 
Tabel 2. Faktor overload yang diperbolehkan dalam waktu pendek untuk trafo distribusi

\begin{tabular}{|c|c|}
\hline $\begin{array}{c}\text { Duration of } \\
\text { Overload }\end{array}$ & $\begin{array}{c}\text { Multiple of rated } \\
\text { kVA }\end{array}$ \\
\hline $10 \mathrm{~s}$ & 10.5 \\
\hline $60 \mathrm{~s}$ & 4.7 \\
\hline $10 \mathrm{~min}$ & 2.6 \\
\hline $30 \mathrm{~min}$ & 1.9 \\
\hline $2 \mathrm{~h}$ & 1.4 \\
\hline
\end{tabular}

Tabel ini memberikan petunjuk faktorfaktor pengali dari down-rating kVA trafo distribusi untuk NGT. Jadi, kalaupun dalam perhitungan sudah ditemukan berapa kapasitas trafo, maka dalam implementasinya kapasitas trafo bisa diturunkan sesuai dengan durasi yang dipilih tapi alat tetap dalam keadaan aman. Dalam kajian ini akan diambil durasi beban lebih 60 detik dengan faktor 4,7. Sehingga, trafo yang akan dipakai pada skema proteksi berkapasitas:

$$
\begin{aligned}
S_{T R} & =\frac{175}{4,7} \\
& =37,23 \mathrm{kVA}
\end{aligned}
$$

\section{G. KESIMPULAN}

- NGT diperlukan untuk mereduksi arus gangguan tanah sehingga generator aman, khususnya untuk generator yang berkapasitas tinggi.

- NGT dibutuhkan dalam skema proteksi stator generator $100 \%$ dari gangguan tanah.

- NGT dirancang sesuai dengan spesifikasi generator, khususnya yang terkait dengan kapasitansi sistem komponen dan jaringan.

- Generator 802 MVA, 22,8 Kv untuk pengembangan sistem proteksi generator dari gangguan tanah diperlukan NGT dengan kapasitas 37 kVA, $15000 \mathrm{~V} / 240 \mathrm{~V}$ dengan resistor sekunder $0,38 \Omega$, $150 \mathrm{~kW}$.

\section{DAFTAR PUSTAKA}

[1] Klingerman, N. and Dale Finney, Satish Samineni, Normann Fischer, and Derrick Haas. 2015. Understanding Generator Stator Ground Faults and Their Protection Schemes. Atlanta, Georgia: Duke Energy \& Schweitzer Engineering Laboratories, Inc.

[2] IEEE . 1995. IEEE Std C37.102 Guide for AC Generator Protection. USA: IEEE, Inc.

[3] IEEE. 1993. IEEE Std C37.101 Guide for Generator Ground Protection. USA: IEEE, Inc.

[4] IEEE. 2017. IEEE Std C62.92.2 2017 Guide for The Application of Neutral Groundingin Electrical Utility Systems, Part II - Synchronous Generator Systems. New York, USA: IEEE, Inc

[5] Xiaobo L., 2010, The Research and Exploiture of Subharmonic Injection Scheme for Generator Stator Ground Protection, China International Conference on Electricity Distribution

[6] IEEE Std C37.102 ${ }^{\text {TM}}-20062006$ IEEE Guide for AC Generator Protection, New York, USA: IEEE, Inc

[7] Kulkarni, S. V. and Khaparde, S. A. 2004. Transformer Engineering Design and Practice. Mumbai, India: Indian Institute of Technology, 2004.

[8] Harlow, James H. 2012. Electric Power Transformer Engineering. New York : Taylor \& Francis Group, LLC, 2012. 13:978-1-4398-5636-9. 